Arch Histol Cytol, 73 (2): 91-93 (2010)

\title{
Fixation conditions affect the immunoreactivity of gustducin in rat vallate taste buds
}

\author{
Maiko Haga and Sumio Yoshie \\ Department of Histology, The Nippon Dental University School of Life Dentistry at Niigata, Niigata, Japan
}

\begin{abstract}
Summary. This study aimed to examine gustducin immunoreactivities when adopting various immunostaining conditions in rat vallate taste buds. The occurrence and intensity of the immunoreactivities exhibited specific patterns in accordance with the fixation time. The immunoreactions were localized to only taste hairs, the upper part of the taste bud, after short fixation periods but then to the cell-body cytoplasm excluding the taste hairs after long fixation periods. These immunohistochemical data suggest that the staining protocols, especially the fixation time, cause discrepancies in gustducin immunoreactivities.
\end{abstract}

\section{Introduction}

The taste bud, a chemoreceptive primary sensory organ for gustation, is composed of specialized epithelial cells and neurites. Extensive morphologic studies have revealed that taste buds comprise sensory cells that form synapses with afferent sensory nerve fibers along with other nonsynapsing sustentacular and precursor cells (Hirata, 1966; Murray et al., 1969; Graziadei and DeHan, 1971; Uchida, 1980). Apical microvilli called taste hairs are localized at the apical part of all the cells, except for the basal cell.

Received May 19, 2010

Address for correspondence: Maiko Haga, D.D.S., Ph.D., Department of Histology, The Nippon Dental University School of Life Dentistry at Niigata, 1-8 Hamaura-cho, Chuo$\mathrm{ku}$, Niigata 951-8580, Japan

Tel: +81-25-267-1500, Fax: +81-25-267-1134

E-mail: h-maiko@ngt.ndu.ac.jp
Gustation receptors and signal transduction molecules have been progressively elucidated (Kinnamon and Margolskee, 1996; Lindemann, 1996; Herness and Gilbertson 1999; Gilbertson et al., 2000). Among these molecules corresponding to the recepto-transduction system, gustducin has been identified as a taste-cellspecific $\mathrm{G} a$ protein that is most closely related to transducin (McLaughlin et al., 1992). Although gustducin should be expected to bind to receptors located in the plasma membrane of taste hairs, numerous studies on mammalian taste buds have shown the immunoreaction for gustducin throughout the cytoplasm (Tabata et al., 2003; Miura et al., 2007; Ohkubo et al., 2007; Merigo et al., 2008; Yamazaki et al., 2010). Taste hairs are often immuno-negative after fixing with a fixative containing $4 \%$ paraformaldehyde for relatively long periods of $8 \mathrm{~h}$ or more. Why does any immunopositivity for gustducin fail to be exhibited at the taste hair - that should include gustducin? Hypothesizing that some methodological factors disturb the immunoreaction at the taste hair, we altered the immunohistochemistry by changing of the fixation time and diluting the antibody as a first step to solve this problem.

\section{Materials and Methods}

Male Wistar rats weighting 250-300 g were used in this study. Animal protocols were devised and performed in accordance with the guidelines of The Nippon Dental University for the Care and Use of Laboratory Animals.

\section{Tissue preparation}

Tongues were removed from animals under anesthesia and rapidly frozen in isopentane precooled to $-35^{\circ} \mathrm{C}$. 

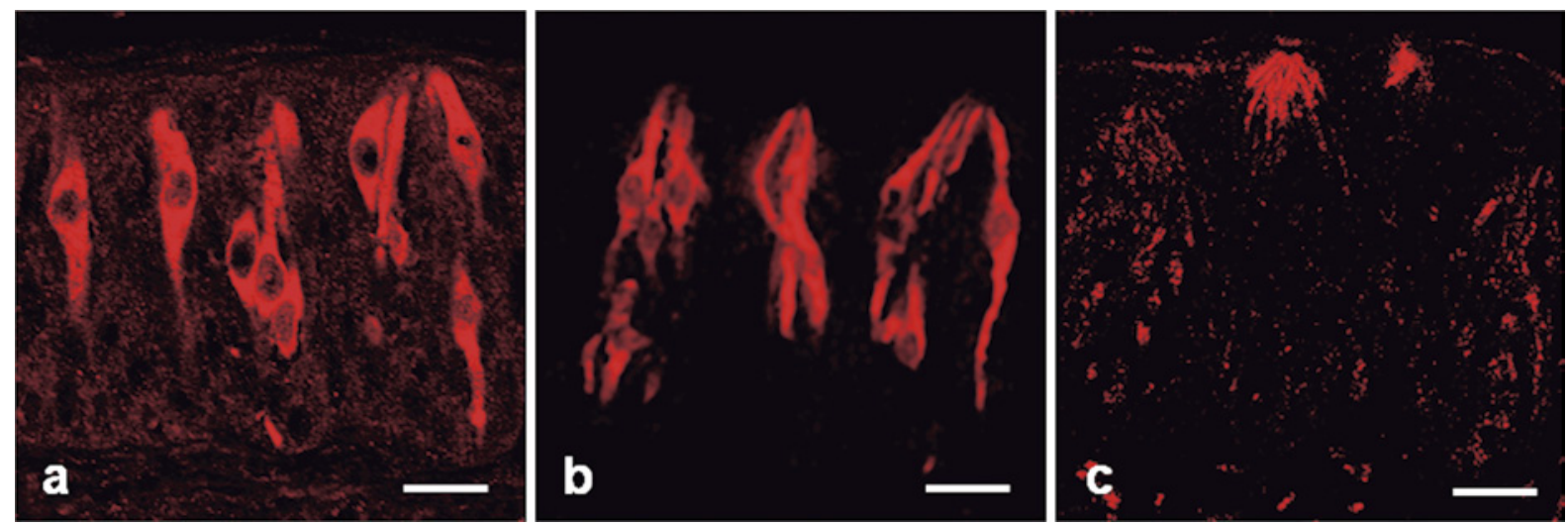

Fig. 1: Immunohistochemistry for gustducin when diluted 1:1600 (a, b) and 3200 (c), after fixation overnight following a transcardiac perfusion (a), fixation for $2 \mathrm{~h} \mathrm{(b)}$, and for $5 \mathrm{~min}(\mathbf{c})$ in the rat taste buds. Immunoreactions are localized to the cell-body cytoplasm - excluding the taste hairs - after long fixation periods $(\mathbf{a}, \mathbf{b})$; on the other hand, they are localized to only taste hairs but not the cell body after shorter fixations (c). Laser scanning micrographs. Scale bars $=20 \mu \mathrm{m}$

Frozen sections were produced at a thickness of $6 \mu \mathrm{m}$ on a cryostat, mounted on glass slides, and immediately fixed by immersion in $4 \%$ paraformaldehyde in a 0.07 $\mathrm{M}$ phosphate buffer ( $\mathrm{pH}$ 7.3). The fixation periods by immersion were set at $1,5,10,15$, and $30 \mathrm{~min}$, and 1 and $2 \mathrm{~h}$. In addition, frozen sections were also cut from tongues which were removed following fixation with a transcardiac perfusion, immersed overnight in the same fixative and frozen in the same manner as described above.

\section{Immunohistochemical protocol}

The primary antibody against anti-rat gustducin raised in rabbits was purchased from Santa Cruz Biotechnology (USA). The secondary antibody, fluorescent dyeconjugated IgG (Alexa Fluor 555-labeled anti-rabbit IgG), was from Molecular Probes (USA). For immunostaining by the indirect fluorescence method, individual tissue sections were incubated overnight at $4{ }^{\circ} \mathrm{C}$ with the antibody against gustducin (dilutions: 1:200 to 1:3200). After incubation, these sections were exposed to Alexa Fluor 555-labeled anti-rabbit IgG (1:200) for $2 \mathrm{~h}$ at room temperature. The stained sections were observed and photographed under a fluorescence microscope equipped with a digital imaging system and confocal laser scanning microscope (AxioCam and LSM 710, Carl Zeiss, Germany).

The specificity of the immunoreactions was checked by using the following two negative controls: omission of the first step of the immunostaining, and the incubation of tissue sections with normal rabbit serum in place of the primary antibody.

\section{Results and Discussion}

Immunoreactions with the two negative control procedures were completely negative, confirming the specificity of the immunohistochemical findings (data not shown).

The present study revealed differences in immunoreactions for gustducin by altering the fixation conditions. Specific staining was observed in long-time fixation (Fig. $1 \mathrm{a}, \mathrm{b})$. However, immunoreaction for gustducin in longtime fixation appeared in only the cell-body cytoplasm (Fig. 1a, b); taste hairs reacted for gustducin only in short-time fixation (Fig. 1c). Dilution of the antibody did not affect the tendency of immunoreactions in the same fixation time (data not shown).

Previous papers described how an optimal immunohistochemical expression depended on the type and concentration of antibodies, the antigen retrieval method, the kind of the buffers used as diluents and rinsing solutions, and the immunohistochemical detection system (Grube, 1980; Scopsi et al., 1986; Grube and Yoshie, 1989; Ramos-Vara and Miller, 2006; Cîmpean et al., 2007). It is reasonable to consider that the fixation period affected the immunostaining ability. This strongly supports the possibility that the fixation time is a crucial parameter in results.

The present finding on the methodological conditions 
of the protocol should help further detailed studies on gustducin immunoreaction in the taste buds. Care must be taken to employ the most suitable protocol for the purpose of the experiment since the results differed by changing the conditions.

\section{Acknowledgements}

The authors cordially thank the staff of the Department of Histology, The Nippon Dental University School of Life Dentistry at Niigata, for their encouragement throughout this study.

\section{References}

Cîmpean AM, Raica M, Izvernariu DA, Tătucu D: Lymphatic vessels identified with podoplanin. Comparison of immunostaining with three different detection systems. Rom J Morphol Embryol 48: 139143 (2007).

Gilbertson TA, Damak S, Margolskee RF: The molecular physiology of taste transduction. Curr Opin Neurobiol 10: 519-527 (2000).

Graziadei PP, DeHan RS: The ultrastructure of frogs' taste organs. Acta Anat (Basel) 80: 563-603 (1971).

Grube D: Immunoreactivities of gastrin (G-) cells. II. Non-specific binding of immunoglobulins to G-cells by ionic interactions. Histochemistry 66: 149-167 (1980).

Grube D, Yoshie S: Immunohistochemistry of chromogranin A and B, and secretogranin II in the canine endocrine pancreas. Arch Histol Cytol 52: 287298 (1989).

Herness MS, Gilbertson TA: Cellular mechanisms of taste transduction. Annu Rev Physiol 61: 873-900 (1999).

Hirata Y: Fine structure of the terminal buds on the barbels of some fishes. Arch Histol Jpn 26: 507-523 (1966).

Kinnamon SC, Margolskee RF: Mechanisms of taste transduction. Curr Opin Neurobiol 6: 506-513 (1996).

Lindemann B: Taste reception. Physiol Rev 76: 718-766 (1996).
McLaughlin SK, McKinnon PJ, Margolskee RF: Gustducin is a taste-cell-specific G protein closely related to the transducins. Nature 357: 563-569 (1992).

Merigo F, Benati D, Galiè M, Crescimanno C, Osculati F, Sbarbati A: Immunohistochemical localization of cystic fibrosis transmembrane regulator and clara cell secretory protein in taste receptor cells of rat circumvallate papillae. Chem Senses 33: 231-241 (2008).

Miura H, Nakayama A, Shindo Y, Kusakabe Y, Tomonari $\mathrm{H}$, Harada S: Expression of gustducin overlaps with that of type III IP3 receptor in taste buds of the rat soft palate. Chem Senses 32: 689-696 (2007).

Murray RG, Murray A, Fujimoto S: Fine structure of gustatory cells in rabbit taste buds. J Ultrastruct Res 27: 444-461 (1969).

Ohkubo Y, Yokosuka H, Kumakura M, Yoshie S: Existence of subtypes of gustducin-immunoreactive cells in the vallate taste bud of guinea pigs. Arch Histol Cytol 70: 291-296 (2007).

Ramos-Vara JA, Miller MA: Comparison of two polymerbased immunohistochemical detection systems: ENVISION+ and ImmPRESS. J Microsc 224: 135-139 (2006).

Scopsi L, Wang BL, Larsson LI: Nonspecific immunocytochemical reactions with certain neurohormonal peptides and basic peptide sequences. J Histochem Cytochem 34: 1469-1475 (1986).

Tabata S, Wada A, Kobayashi T, Nishimura S, Muguruma $\mathrm{M}$, Iwamoto $\mathrm{H}$ : Bovine circumvallate taste buds: taste cell structure and immunoreactivity to $a$-gustducin. Anat Rec A Discov Mol Cell Evol Biol 271:217-224 (2003).

Uchida T: Ultrastructural and histochemical studies on the taste buds in some reptiles. Arch Histol Jpn 43: 459478 (1980).

Yamazaki M, Fujii S, Ochiai A: Reduction of type II taste cells correlates with taste dysfunction after X-ray irradiation in mice. J Oral Pathol Med 39: 212-218 (2010). 